\title{
A Quality Assessment of Titanium Castings Produced in an Experimental Short-Heating-Cycle Investment
}

\author{
Gelson Luis Adabo ${ }^{a *}$, Gustavo Rocha de Paula ${ }^{b}$ Fabiane Nogueira ${ }^{a}$, \\ Laiza Maria Grassi Fais ${ }^{a}$, Oscar Peitl
}

\author{
${ }^{a}$ Departamento de Materiais Odontológicos e Prótese, Faculdade de Odontologia, \\ Univ Estadual Paulista - UNESP, Rua Humaitá, 1680, CEP 14801-903, Araraquara, SP, Brasil \\ ${ }^{b}$ Materials Engineering Department, Federal University of São Carlos - UFSCar, \\ Rod. Washington Luis, Km 235, CEP 13565-905, São Carlos, SP, Brasil
}

Received: May 9, 2013; November 7, 2013

\begin{abstract}
The aim of this study was to evaluate the quality of casting produced in an experimental short-term heating-cycle investment. Thus, reaction layer and castability of titanium casting using an experimental spinel-based investment (VR) with short heating cycle were compared with the commercial short-heating-cycle spinel-based investment Trinell (TR), the silica-phosphate-based investment Rematitan Plus (RP), and the conventional spinel-based investment Rematitan Ultra (RU). VR has polymeric fibers added to inorganic particles. Reaction layer assessments were carried out using Vickers hardness and elemental analysis using dispersive X-ray microanalysis (EDX). Mesh patterns were used for castability test, and powder characterization was made by scanning electron microscopy (SEM). Hardness evaluation showed no difference among the investments between 100 and $200 \mu \mathrm{m}$. The most important contaminant element for VR, TR, and RU was oxygen. Higher levels of mold filling were found for TR, VR, and RU compared with that obtained with RP. The quality of castings, characterized by means of the assessments of reaction layer and castability, made from the VR was similar to the commercial investments TR and RU but superior to the RP.
\end{abstract}

Keywords: dental casting investment, dental alloys, titanium alloy

\section{Introduction}

Titanium (Ti) is considered to be the most important alternative to gold alloy for use in oral rehabilitation because of its high corrosion resistance, excellent biocompatibility, low density, high strength/weight ratio, and adequate mechanical properties. However, titanium can react with elements of the investment materials, atmospheric oxygen and nitrogen, creating a contaminated surface layer ${ }^{1}$ with an increased hardness, brittleness, and susceptibility to corrosion ${ }^{1,2}$. Special casting technologies have been developed to deal with these issues, including specific investments and special casting machines ${ }^{3}$.

The most common investments used for titanium are phosphate-bonded investments based on silica phases (crystalline quartz or cristobalite) that are inexpensive and exhibit a thermal expansion compatible with Ti casting shrinkage ${ }^{4}$. However, $\mathrm{SiO}_{2}$ can be reduced by $\mathrm{Ti}$, and this affects the physical and mechanical properties of the titanium castings $^{5-12}$. On the other hand, spinel-based investments produce enough thermal expansion to compensate for the Ti casting shrinkage and produce a minor reaction layer thickness but are more expensive $e^{10,13-21}$. Another concern about titanium castings is deficient mold filling that may be related to the casting machine, temperature gradient between molten metal and mold temperature, and reactions

*e-mail: adabo@foar.unesp.br between molten titanium and investment materials, beyond permeability of the investment ${ }^{19-21}$.

In general, investments for titanium casting require processing periods of 7 to 10 hours. Alternatively, a short-cycle spinel-based investment Trinell (Dentaurum, Ispringen, Germany), whose thermal cycle sets with a drying in a microwave oven and then heating starts in a furnace preheated to $400{ }^{\circ} \mathrm{C}$ for 5 hours, was developed ${ }^{22}$. Recently, an experimental spinel-based investment, developed by Vitrovita (Sao Carlos, Brazil), uses hydratable alumina cement as a binding agent that is mixed with distilled water. This investment has a thermal cycle that starts at room temperature, but heating is carried out at a high rate $\left(10{ }^{\circ} \mathrm{C} / \mathrm{min}\right)$. If this experimental investment enables the production of castings with good quality, the lower costs will be the main advantages when it is compared with the commercial available investments. The reduced processing time and the absence of any special liquid may have facilitated the casting, reducing the laboratory costs. Moreover, although there is no scientific study about the influence of processing time on the quality of castings, the manufacturer suggested that processing time reduction can reduce the oxidation of titanium.

The aim of this study was to evaluate the quality of casting produced in an experimental short-term heatingcycle investment. Thus, reaction layer and castability 
of titanium casting using the experimental spinel-based investment (VR) with short heating-cycle were compared with the commercial short-heating-cycle spinel-based investment Trinell (TR), the silica-phosphate based investment Rematitan Plus (RP; Dentaurum - Ispringem, Germany), and the conventional spinel-based investment Rematitan Ultra (RU; Dentaurum - Ispringen, Germany). Here, the null hypothesis is that the quality of castings produced in experimental short-term heating-cycle investment (VR) does not differ significantly in terms of castability or the reaction layer of castings from commercial investments TR, RP, and RU. In addition, powder particles of the investments were characterized.

\section{Experimental}

According to the manufacturer, the experimental investment (VR) (Vitrovita, Sao Carlos, Brazil) is a magnesia spinel-based investment, and its binder is hydratable alumina cement $(\mathrm{P} / \mathrm{L}$ ratio $=0.20)$ instead of the magnesia salts and colloidal silica solutions usually found in commercial investments. Small amounts of organic phases and zirconia oxide are also added to the experimental investment.

The other selected commercial brands represent different types of investments: one is the phosphate-bonded investment Rematitan plus (RP), one is the conventional spinel-based material Rematitan Ultra (RU), and one is the fast thermal cycle material Trinell (TR). Table 1 describes the investments used in this study.

\subsection{Scanning electron microscopy of investment powders}

Investment powders $(5 \mathrm{~g})$ were dispersed in $50 \mathrm{ml}$ of isopropyl alcohol for 2 minutes using an ultrasonic device. A droplet of each solution was poured on a glass microscope slide, and the images were captured using a scanning electric microscope FEI TMP-XL30 (FEI Company, Hillsboro, USA). Back-scattered electron images (BSE images) of these investment powders were taken at $\times 1000$ magnification.

\subsection{Castability test}

As previously described ${ }^{10}$, Nylon mesh patterns $(n=5)$ $(14 \times 14 \mathrm{~mm}$, with 49 internal squares and 0.5 -mm filament diameters) were used to measure the castability. They were attached to 2 wax runner bars of $4.0 \mathrm{~mm}$ in diameter placed along the 2 edges at angles of 90 degrees. Each wax pattern was individually sprued (Figure 1) using a 5-gauge sprue wax (Dentaurum JP Winkelstroeter KG, Pforzheim, Germany).
Before the inclusion, an image of the pattern was acquired in an image analysis system Leica QWin image (Leica Microsystems Imaging Solutions Ltd, Cambridge, England). The total extension of the filaments (in $\mathrm{mm}$ ) was measured $^{10,22}$.

Each pattern was individually included in the casting ring. The casting ring was lined with a single layer of cellulose ring liner (KeraVlies, Dentaurum JP, Winkelstroeter $\mathrm{KG}$, Pforzheim, Germany), and the wax pattern was coated with an anti-bubbles liquid (Kota Ind. e Comercio, Ltda, Sao Paulo, Brazil). Investments were mixed in a vacuum mixer (Turbo Mix, E.D.G. Equipamentos e Controles, Ltda., Sao Carlos, Brazil) for 60 seconds with the powder/liquid $(\mathrm{P} / \mathrm{L})$ ratio suggested by the manufacturers (Table 1$)$. It was poured under vibration into the casting ring. Two hours after mixing, casting rings of $\mathrm{VR}, \mathrm{RU}$, and $\mathrm{RP}$ were heated in electric furnace (EDGCON 5P, E.D.G. Equipamentos e Conttroles Ltda., Sao Carlos, Brazil). For TR, one hour after the mixture, casting rings were heated in microwave oven during 8 minutes and transferred to the electric furnace at $400{ }^{\circ} \mathrm{C}$. Heating program for investments studied is shown in Table 2.

The casting procedure was performed in an Ar-arc vacuum-pressure casting machine Discovery Plasma (EDG Equipamentos, Sao Carlos, Brazil). Castings were divested and cleaned in distilled water in an ultrasonic cleaner (Inpec Electronics, Vinhedo, Brazil). After the

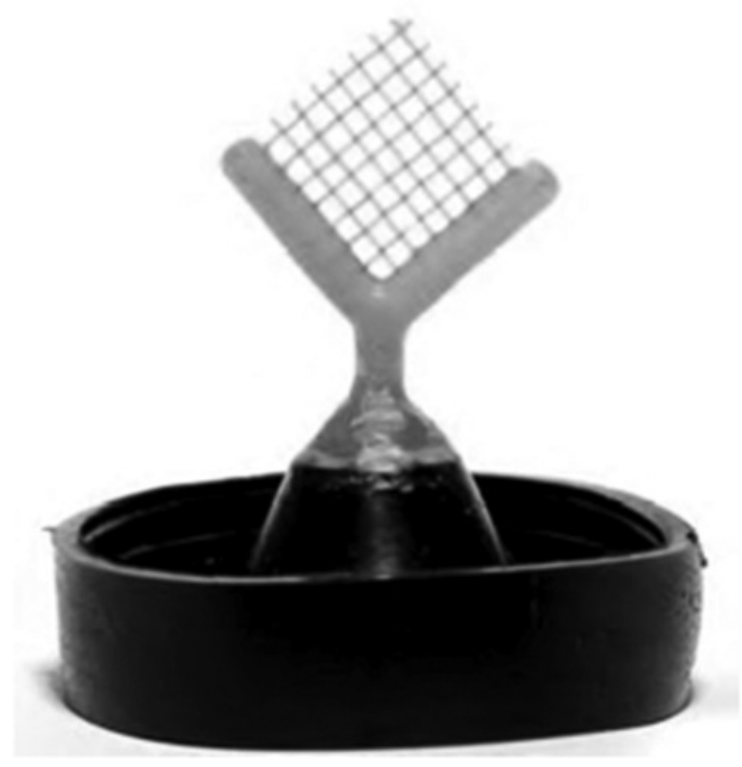

Figure 1. Wax pattern for castability evaluation.

Table 1. Investment materials studied.

\begin{tabular}{llccc}
\hline \multicolumn{1}{c}{ Commercial brand } & \multicolumn{1}{c}{ Type } & P/L ratio & Batch numbers & Manufacturer \\
\hline Experimental (VR) & Spinel-based investment & 0.20 & Vitrovita, Sao Carlos, SP, Brazil \\
Rematitan Ultra (RU) & Spinel-based investment & 0.14 & 050820 & Dentaurum, Ispringen, Germany \\
Trinell (TR) & Spinel-based investment & 0.14 & 040820 & Dentaurum, Ispringen, Germany \\
Rematitan Plus (RP) & Phosphate-bonded investment & 0.16 & 060645 & Dentaurum, Ispringen, Germany \\
\hline
\end{tabular}


cleaning (Figure 2), castings were digitally photographed again, and the number of completely cast segments was measured with the image analysis system. The castability index was determined by the number of the completely cast segments as a percentage of the pattern initially photographed $^{10}$.

The data were transformed using logarithmic transformation to homogenize the variance. One-way analysis of variance (ANOVA) was used to determine if observed differences were statistically significant $(\alpha=0.05)$. The post hoc Tukey's HSD test was used to determine if significant differences existed among the materials studied. The statistical tests were performed with the software SPSS for windows 15.0 (IBM, Chicago, USA).

\subsection{Reaction layer}

Disc-shaped patterns of $6 \times 3 \mathrm{~mm}$ were fabricated with green casting wax StarWax CB (Dentaurum, Ispringen, Germany). Investing and casting procedures were performed as described for the castability test.

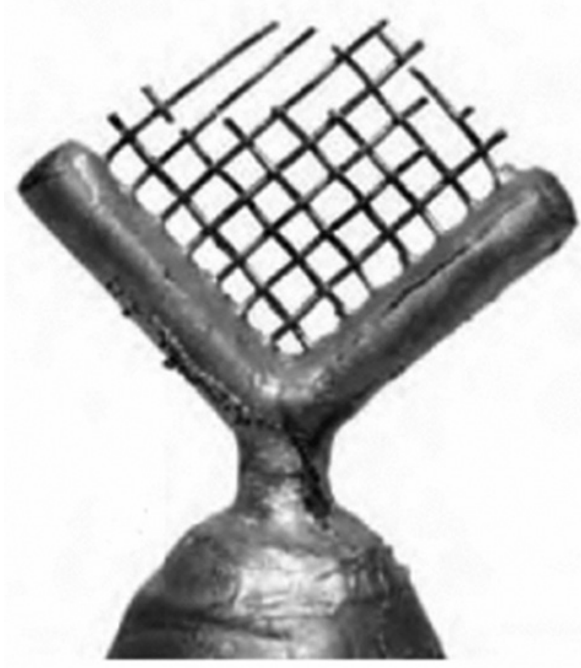

Figure 2. Casting for castability evaluation with incomplete cast segments.
The castings $(n=8)$ were embedded in an epoxy resin Epo-Thin (Buehler UK Ltd., Coventry, England) and progressively ground with waterproof $\mathrm{SiC}$ abrasive papers - \#320, \#400, \#600, \#800, \#1200, \#1500, and \#2000 (Norton Abrasivos do Brazil, Sao Paulo, Brazil) under running tap water. The polishing was finished with diamond suspensions (3 and $1 \mu \mathrm{m}$ ) Metadi Supreme (Buehler, Lake Bluff, USA) and $0.06 \mu \mathrm{m}$ colloidal silica Mastermet (Buehler, Lake Bluff, USA) using Ultrapol and Microcloth polishing cloths (Buehler, Lake Bluff, USA).

Surface hardness was measured using a Vickers hardness tester Micromet 2100 (Buehler, Lake Bluff, USA) with load of $1.96 \mathrm{~N}$ and a 15-second loading time. Hardness measurements were made by tracking the surface of the exposed metal from the periphery to the center, with the following distances from the outer edge: 25, 50, 100, 150, and $200 \mu \mathrm{m}$. The hardness data were analyzed using a 2 -way ANOVA and the Tukey HSD test $(\alpha=0.05)$ with the software SPSS for windows 15.0.

The elemental composition analysis of the interfacial zone reaction was carried out at 25, 50, 100, 150, and $200 \mu \mathrm{m}$ from the surface using energy-dispersive X-ray microanalysis (EDX) in a scanning electron microscope JEOL-JSM T-330 A (JSM, Tokyo, Japan). The analyses were performed in EDX Link Analytical, model QX 2000, with Microscopy Electron LEO (Carl Zeiss Microscopy Ltd, Cambridge, United Kingdom) and with the Oxford detector (Oxford Instruments, Bristol, United Kingdom), $20 \mathrm{kV}$ and distance of $25 \mathrm{~mm}$. The percentage of the elements $\mathrm{O}, \mathrm{Mg}$, $\mathrm{Al}, \mathrm{Si}, \mathrm{P}, \mathrm{Zr}$, and Ti was recorded (weight \%).

\section{Results and Discussion}

\subsection{Investments powders}

Figures 3 to 6 show BSE images of different investment powders taken using a scanning electron microscope $(\times 1000)$.

The RP investment has the largest particle sizes (Figure 3), whereas RU, TR, and VR have smaller particle sizes. Additionally, RU and TR have small whisker fibers in their composition (Figures 4 and 5). VR also has fibers (Figures 6), but these are large and symmetrical, unlike the smaller whisker fibers found in RU and TR. The symmetry of

Table 2. Heating program for investments studied.

\begin{tabular}{|c|c|c|c|c|c|}
\hline Material & Program & Phase 1 & Phase 2 & Phase 3 & Phase 4 \\
\hline \multirow{3}{*}{ Experimental (VR) } & Temperature & $1000^{\circ} \mathrm{C}$ & $500{ }^{\circ} \mathrm{C}$ & & \\
\hline & Rate & $10^{\circ} \mathrm{C} / \mathrm{min}$ & $5^{\circ} \mathrm{C} / \mathrm{min}$ & & \\
\hline & Step & $30 \mathrm{~min}$ & $30 \mathrm{~min}$ & & \\
\hline \multirow{3}{*}{ Rematitan Ultra (RU) } & Temperature & $250^{\circ} \mathrm{C}$ & $885^{\circ} \mathrm{C}$ & $430^{\circ} \mathrm{C}$ & \\
\hline & Rate & $5^{\circ} \mathrm{C} / \mathrm{min}$ & $5^{\circ} \mathrm{C} / \mathrm{min}$ & $5^{\circ} \mathrm{C} / \mathrm{min}$ & \\
\hline & Step & $90 \mathrm{~min}$ & $30 \mathrm{~min}$ & $30 \mathrm{~min}$ & \\
\hline \multirow{3}{*}{ Trinell (TR) } & Temperature & & $870^{\circ} \mathrm{C}$ & $400^{\circ} \mathrm{C}$ & \\
\hline & Rate & $400^{\circ} \mathrm{C}$ & $5^{\circ} \mathrm{C} / \mathrm{min}$ & $5^{\circ} \mathrm{C} / \mathrm{min}$ & \\
\hline & Step & & $20 \min$ & $30 \mathrm{~min}$ & \\
\hline \multirow{3}{*}{ Rematitan Plus (RP) } & Temperature & $150^{\circ} \mathrm{C}$ & $250^{\circ} \mathrm{C}$ & $1000^{\circ} \mathrm{C}$ & $430{ }^{\circ} \mathrm{C}$ \\
\hline & Rate & $5^{\circ} \mathrm{C} / \mathrm{min}$ & $5^{\circ} \mathrm{C} / \mathrm{min}$ & $5^{\circ} \mathrm{C} / \mathrm{min}$ & $5^{\circ} \mathrm{C} / \mathrm{min}$ \\
\hline & Step & $90 \mathrm{~min}$ & $90 \min$ & $60 \mathrm{~min}$ & $30 \min$ \\
\hline
\end{tabular}




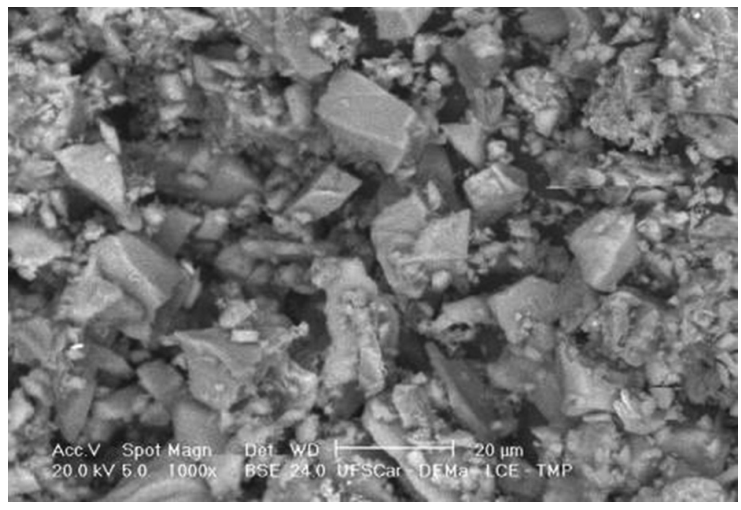

Figure 3. BSE $(\times 1,000)$ of RP powder.

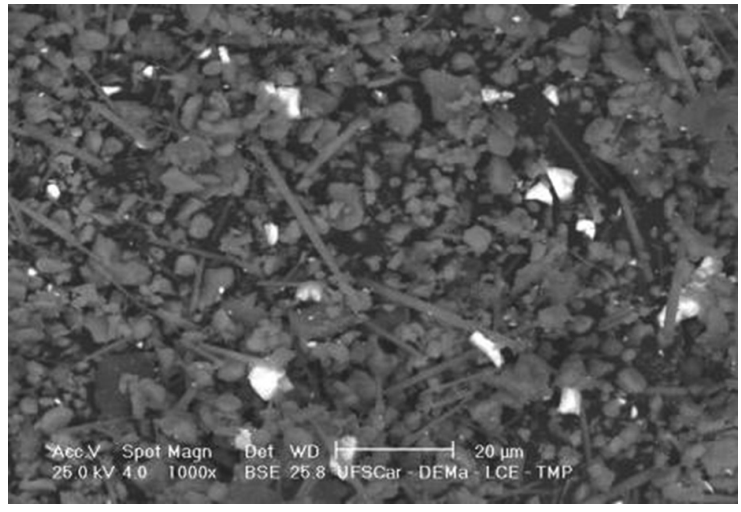

Figure 4. BSE $(\times 1,000)$ of RU powder.

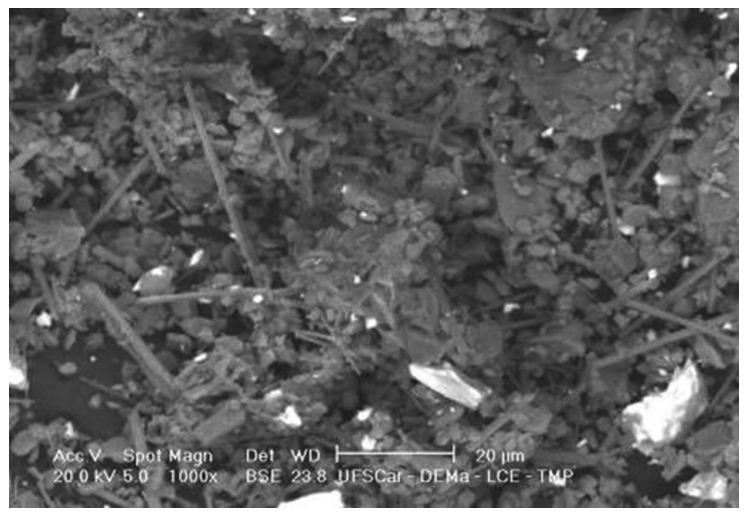

Figure 5. BSE $(\times 1,000)$ of TR powder.

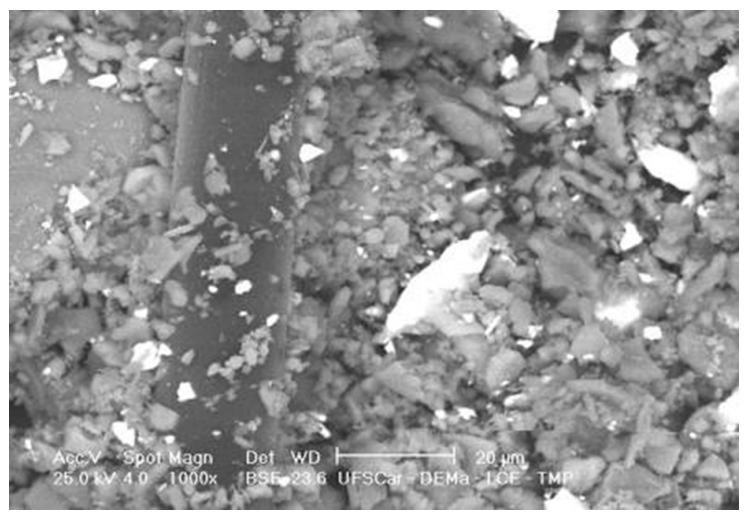

Figure 6. BSE $(\times 1,000)$ of VR powder. these large fibers suggests that they are synthetic. Figures 4 and 5 showed that there are no differences in the color of either the whisker fibers or the matrix powders in RU and TR, suggesting that the fibers are inorganic. On the other hand, Figure 6 shows that VR's fibers are darker than its powders (matrix), suggesting that its fibers are organic.

The particle size influences the packaging and, thus, the porosity of the investment after firing, which in turn affects the castability. Synthetic fibers of VR are organics and decomposed during heating at high temperatures, leaving permeable pores that will increase the castability. Moreover, the particle size can influence the ceramic phases formed during the burning of the investment influencing the permeability, castability, and reaction layer. For example, the experimental investment (VR) has the addition of alumina $\left(\mathrm{Al}_{2} \mathrm{O}_{3}\right)$ to form magnesium-alumina spinel during firing (expansion phase). The residual alumina, in large amounts, may have a stronger reaction with the titanium than to the spinel.

The fast-heating-cycle investments TR and VR require approximately 5 hours of processing time. However, TR must be first heated in a microwave oven, which according to the manufacturer, is responsible for drying the investment. One interesting aspect of VR is its binder, which is composed of hydratable alumina cement. This binder is produced by alumina calcinations that generate a high surface area transition phase called rho-alumina ${ }^{23}$. During its hydration, a thick layer of gel is formed and partially crystallizes into bohemite and bayerite crystals. However, the major gel phase remains interlocked around the crystals. According to Cardoso et al. ${ }^{23}$, the low air permeability of this gel phase serves to avoid rapid water removal during heating and consequently increases the possibility of explosive spalling under fast and continuous heating. Nevertheless, high permeability ceramics can be obtained by adding organic fibers $^{24}$. The investment explosion likely does not occur to the VR investment probably because of the organic nature of the fibers in its formulation. The main reason is that the fibers after mold firing at high temperatures generate permeable paths that increase the rate of water removal ${ }^{24}$.

\subsection{Castability test}

Like the interference of thermal expansion on crown marginal misfit, castability can also directly influence the casting precision. Rounded and incomplete margins are not acceptable ${ }^{14,15}$, and these defects might be related to casting temperature, mold temperature, casting machine, and mold permeability.

Statistically significant differences in the castability index mean were demonstrated using a one-way ANOVA $\left(F_{3,16}=26.6831 ; p<0.001\right)$. The Tukey test showed that there were no significant differences among the spinel-based investments: VR $(57.1 \pm 5.1 \%)$, RU (55.6 $\pm 14.5 \%)$, and TR $(61.3 \pm 16.2)$, which had significantly higher castability indexes than the phosphate-bonded material RP $(9.8 \pm 3.8 \%)$.

Low castability in phosphate-bonded investments may be mainly because of the liquid phases generated at higher temperatures among phosphate, silica, and magnesia oxides. These liquid phases fill pores and, thus, decrease the 
permeability of the ceramic molds. For VR investment, the presence of gel phase reduces air permeability, and because of this, the manufacturer included organic phase to improve the investment permeability after firing. On the other hand, spinel-based investments RU and TR are mainly composed of magnesia, alumina, and zirconia, with binders based on magnesia salts ${ }^{25}$.

Nevertheless, high permeability itself may not guarantee complete mold filling. Pieraline et al. ${ }^{11}$ studied the apparent porosity and castability of castings made in 3 phosphatebonded investments -Castorit Super C (Dentaurum, Ispringen, Germany), Rematitan Plus and Rema Exakt (Dentaurum, Ispringen, Germany), and a spinel-based material Rematitan Ultra. The results indicate that Castorit Super C had higher apparent porosity than Rematitan Plus and Rema Exakt and a similar porosity to the spinel-based material. However, the castability of Castorit Super C was not statistically different from the other phosphate-bonded investments that demonstrated far poorer mold filling than those made in the spinel-based investments. Reza et al. ${ }^{13}$ reported that phosphate-bonded investments were less permeable than spinel-based materials. However, the relation between castability and permeability was not ever true because among the spinel-based investments, they found that those materials with the highest permeability did not also have the best castability.

The mold temperature varied slightly among RP, RU, and TR, but the VR casting temperature was between 70 and $100{ }^{\circ} \mathrm{C}$ higher. According to Oliveira et al. ${ }^{10}$, when mold temperatures increased from 50 to $100{ }^{\circ} \mathrm{C}$, the castability was progressively improved. Thus, VR castability might be influenced by its higher mold temperature.

\subsection{Reaction layer}

The reaction layer on the casting surface was studied comprehensively in terms of Vickers hardness and elemental composition. The presence of a contamination zone is undesirable because it adversely affects the mechanical and physical properties of titanium ${ }^{1-7,9,16-18,22}$. Higher hardness values indicate that the titanium is more contaminated.

A two-way ANOVA for Vickers hardness (Table 3) was statistically significant for investment, measurement depth, and the interaction between the investment and measurement depth. To probe the meaning of the interaction term, the decomposition from the two-way ANOVA to one-way ANOVA $\left(\mathrm{F}_{5,54}=145.848, P<0.001\right)$ was performed. The post hoc Tukey HSD test (Table 4) shows that at $25 \mu \mathrm{m}$, the highest value was found for RP, followed by RU and TR, whereas VR showed the lowest value at this level. At $50 \mu \mathrm{m}$, there were no statistically difference among RP, VR, and RU, but TR had lower hardness than RP. From 100 to $200 \mu \mathrm{m}$, there was no statistically difference among castings made with all investments.

The highest values that were found in the first levels of RP was expected because of the $\mathrm{Si}$ and $\mathrm{Al}$ present in phosphate-bonded investments ${ }^{12,17-22}$. At depths greater than $100 \mu \mathrm{m}$, there is no statistically significant difference among the levels of the various investments, revealing that $100 \mu \mathrm{m}$ represents a typical reaction layer thickness.

Table 5 shows an analysis of the elemental composition of the interfacial zone reaction. The contamination decreases from the top to the inner with increasing distance from the exterior surface, and oxygen is the main contaminant in all of the investments studied. However, in the phosphate-bonded investment RP, contamination with $\mathrm{Si}$ and $\mathrm{Al}$ at a higher level than that in the spinel-based materials was found. The element $\mathrm{Zr}$ was found at the highest levels in TR.

Depending on its composition, an investment can supply more contamination by the reduction of oxides, which depends on the free energy of oxide formation ${ }^{18-21}$. The higher level of surface contamination observed in the castings made in the phosphate-bonded investment (RP) might be because the free energy of oxide formation for $\mathrm{SiO}_{2}(-604 \mathrm{~kJ} / \mathrm{mol} \mathrm{O})_{2}$ and $\mathrm{Al}_{2} \mathrm{O}_{3}(-712 \mathrm{~kJ} / \mathrm{mol} \mathrm{O}$ ) are close to that of $\mathrm{TiO}_{2}(-622 \mathrm{~kJ} / \mathrm{mol} \mathrm{O})_{2}$ at $1400{ }^{\circ} \mathrm{C}^{[18]}$. In contrast, the free energy of $\mathrm{MgO}\left(-788 \mathrm{~kJ} / \mathrm{mol} \mathrm{O}_{2}\right)$, which is the main compound of spinel-based investments, is not as close to the $\mathrm{TiO}_{2}^{[19,21]}$.

Table 3. Two-way ANOVA for surface hardness.

\begin{tabular}{lcrrrr}
\hline \multicolumn{1}{c}{ Source } & $d f$ & \multicolumn{1}{c}{ S.Q. } & Mean square & F Value & \multicolumn{1}{c}{$\boldsymbol{P}$} \\
\hline Investment & 3 & 24799.83 & 8266.61 & 17.75 & $<0.01$ \\
Hardness depth & 4 & 1170716.80 & 292679.20 & 628.25 & $<0.01$ \\
Investment $\times$ hardness depth & 12 & 95450.98 & 7954.25 & 17.07 & $<0.01$ \\
Error & 140 & 65221.49 & 465.87 & & \\
Total & 160 & 7381868.53 & & & \\
\hline
\end{tabular}

Table 4. Vickers hardness mean (VHN), standard deviation, and contrast by Tukey test.

\begin{tabular}{|c|c|c|c|c|}
\hline depth Investment & VR & RU & TR & $\mathbf{R P}$ \\
\hline $25 \mu \mathrm{m}$ & $290.2(35.6)^{\mathrm{c}}$ & $344.3(26.4)^{\mathrm{b}}$ & $343.0(31.9)^{b}$ & $437.6(47.5)^{\mathrm{a}}$ \\
\hline $50 \mu \mathrm{m}$ & $215.9(15.4)^{\mathrm{de}}$ & $198.1(12.4)^{\mathrm{de}}$ & $178.8(17.9)^{\mathrm{e}}$ & $229.9(24.1)^{\mathrm{d}}$ \\
\hline $100 \mu \mathrm{m}$ & $158.0(24.8)^{\mathrm{f}}$ & $133.0(5.7)^{\mathrm{f}}$ & $138.6(14.2)^{\mathrm{f}}$ & $138.67(13.0)^{\mathrm{f}}$ \\
\hline $150 \mu \mathrm{m}$ & $142.6(19.9)^{\mathrm{f}}$ & $128.6(4.2)^{\mathrm{f}}$ & $133.7(16.2)^{\mathrm{f}}$ & $132.60(14.1)^{\mathrm{f}}$ \\
\hline $200 \mu \mathrm{m}$ & $138.3(29.9)^{\mathrm{f}}$ & $126.6(4.5)^{f}$ & $133.8(17.3)^{\mathrm{f}}$ & $128.8(11.5)^{\mathrm{f}}$ \\
\hline
\end{tabular}

Different lowercase letters indicate significant difference (Tukey's test $-P<0.05$ ). 
Table 5. EDX elemental composition analysis of the interfacial zone reaction (by weight \%).

\begin{tabular}{|c|c|c|c|c|c|c|c|c|}
\hline & Depth & $\mathbf{O}$ & Mg & Al & Si & $\mathbf{P}$ & $\mathbf{Z r}$ & $\mathbf{T i}$ \\
\hline \multirow{5}{*}{ VR } & $25 \mu \mathrm{m}$ & 6.28 & 0.02 & 0.08 & 0.01 & 0.04 & 0.00 & 93.56 \\
\hline & $50 \mu \mathrm{m}$ & 4.87 & -0.01 & 0.01 & 0.03 & 0.08 & -0.05 & 95.08 \\
\hline & $100 \mu \mathrm{m}$ & 2.46 & -0.03 & 0.01 & 0.01 & 0.03 & 0.13 & 97.40 \\
\hline & $150 \mu \mathrm{m}$ & 0.87 & -0.04 & -0.04 & 0.01 & -0.08 & 0.03 & 99.16 \\
\hline & $200 \mu \mathrm{m}$ & 1.75 & 0.00 & 0.01 & 0.04 & -0.04 & 0.00 & 98.24 \\
\hline \multirow{5}{*}{ RU } & $25 \mu \mathrm{m}$ & 6.44 & -0.01 & 0.06 & 0.03 & -0.01 & 0.11 & 93.38 \\
\hline & $50 \mu \mathrm{m}$ & 5.97 & -0.01 & 0.03 & 0.02 & 0.03 & -0.01 & 93.96 \\
\hline & $100 \mu \mathrm{m}$ & 3.42 & 0.10 & 0.03 & 0.04 & 0.00 & -0.07 & 96.47 \\
\hline & $150 \mu \mathrm{m}$ & 2.32 & -0.05 & 0.02 & 0.06 & -0.04 & 0.04 & 97.66 \\
\hline & $200 \mu \mathrm{m}$ & 2.86 & 0.05 & 0.00 & 0.02 & 0.06 & -0.15 & 97.15 \\
\hline \multirow{5}{*}{ TR } & $25 \mu \mathrm{m}$ & 5.07 & 0.00 & 0.07 & 0.03 & -0.04 & 0.10 & 94.77 \\
\hline & $50 \mu \mathrm{m}$ & 5.71 & 0.04 & 0.05 & 0.05 & 0.01 & 0.14 & 94.03 \\
\hline & $100 \mu \mathrm{m}$ & 3.12 & 0.05 & 0.04 & 0.00 & -0.01 & 0.16 & 96.65 \\
\hline & $150 \mu \mathrm{m}$ & 1.62 & -0.01 & 0.03 & 0.01 & -0.01 & 0.12 & 98.25 \\
\hline & $200 \mu \mathrm{m}$ & 2.93 & 0.05 & 0.07 & 0.03 & 0.01 & -0.15 & 96.96 \\
\hline \multirow{5}{*}{ RP } & $25 \mu \mathrm{m}$ & 6.14 & -0.02 & 0.36 & 0.63 & 0.03 & -0.08 & 92.95 \\
\hline & $50 \mu \mathrm{m}$ & 4.82 & -0.01 & 0.16 & 0.10 & 0.01 & 0.04 & 94.99 \\
\hline & $100 \mu \mathrm{m}$ & 2.90 & -0.02 & 0.12 & 0.04 & -0.04 & 0.11 & 96.88 \\
\hline & $150 \mu \mathrm{m}$ & 2.32 & 0.00 & 0.14 & 0.04 & -0.08 & 0.10 & 97.49 \\
\hline & $200 \mu \mathrm{m}$ & 1.39 & 0.03 & 0.04 & 0.01 & -0.01 & 0.05 & 98.49 \\
\hline
\end{tabular}

Based on the properties studied in this investigation, the experimental short-heating-cycle investments VR have a high casting quality that makes them a potentially promising alternative to conventional investments, with the advantage of shorter processing times. However, this study has limitations, such as possible interference with the crown marginal fit and the clinical performance of castings made with this new investment, which would be evaluated in future investigations.

\section{References}

1. Atwood RC, Lee PD and Curtis RV. Modeling the surface contamination of dental titanium investment castings. Dental Materials. 2005; 21(2):178-186. http://dx.doi.org/10.1016/j. dental.2004.02.010

2. Papadopoulos T, Zinelis S and Vardavoulias M. A metallurgical study of the contamination zone at the surface of dental Ti castings, due to the phosphate-bonded investment material: the protection efficacy of a ceramic coating. Journal of Materials Science. 1999; 34(15):3639-3646. http://dx.doi. org/10.1023/A:1004639002688

3. Zinelis S. Effect of pressure of helium, argon, krypton, and xenon on the porosity, microstructure, and mechanical properties of commercially pure titanium castings. Journal of Prosthetic Dentistry. 2000; 84(5):575-582. http://dx.doi. org/10.1067/mpr.2000.109479

4. Ferreira AR, Adabo GL, Peitl-Filho O, Rocha SS and Fonseca RG. Evaluation of the thermal shrinkage of titanium and the setting and thermal expansion of phosphate-bonded investments. Journal of Prosthetic Dentistry. 2007; 98(1):24-29. http:// dx.doi.org/10.1016/S0022-3913(07)60034-1

\section{Conclusions}

It was concluded that the experimental short-cycle investment VR provides castings with good quality. This investment has small particles and organic fibers, castability, and reaction layer compatible with spinel-based commercially available investments, but with the main advantage of reducing processing time when compared with Rematitan Ultra and Rematitan Plus and low cost when compared with Trinell.
5. Hsu HC, Kikuchi H, Yen SK and Nishiyama M. Evaluation of different bonded investments for dental titanium casting. Journal of Materials Science: Materials in Medicine. 2005; 16(9):821-825. http://dx.doi.org/10.1007/s10856-005-3585-2

6. Wang RR, Welsch GE and Castro-Cedeno M. Interfacial reactions of cast titanium with mold materials. International Journal of Prosthodontics. 1998; 11(1):33-43.

7. Takahashi J, Kimura H, Lautenschlager EP, Chern-Lin JH, Moser JB and Grenner EH. Casting Pure Titanium into Commercial Phosphate-bonded $\mathrm{SiO}_{2}$ Investment Molds. Journal of Dental Research. 1990; 69(12):1800-1805. http:// dx.doi.org/10.1177/00220345900690120301

8. Takahashi J, Zhang JZ and Okazaki M. Effect of Casting Methods on Castability of Pure Titanium. Dental Materials Journal. 1993;12(2):245-252. http://dx.doi.org/10.4012/ dmj. 12.245

9. Oda Y, Kudoh Y, Kawada E, Yoshinari M and Hasegawa K. Surface reaction between titanium castings and investments. The Bulletin of Tokyo Dental College. 1996; 37(3):129-136.

10. Oliveira PCG, Adabo GL, Ribeiro FR and Rocha SS. The effect of mold temperature on castability of $\mathrm{CP} \mathrm{Ti}$ and $\mathrm{Ti}-$ 
6Al-4V castings into phosphate bonded investment materials. Dental Materials. 2006; 22(12):1098-1102. http://dx.doi. org/10.1016/j.dental.2005.09.004

11. Pieralini ARF, Benjamin CM, Ribeiro RF, Scaf G and Adabo GL. The Effect of Coating Patterns with Spinel-Based Investment on the Castability and Porosity of Titanium Cast into Three Phosphate-Bonded Investments. Journal of Prosthodontics. 2010; 19(7):517-522. http://dx.doi. org/10.1111/j.1532-849X.2010.00629.x

12. Rocha SS, Nogueira F, Pieralini ARF, Ribeiro RF and Adabo GL. Effect of phosphate-bonded investments on titanium reaction layer and crown fit. Brazilian Oral Research. 2010; 24(2):147-152. http://dx.doi.org/10.1590/ S1806-83242010000200004

13. Reza F, Takahashi H, Iwasaki N and Tamaki Y. Effects of investment type and casting system on permeability and castability of CP titanium. Journal of Prosthetic Dentistry. 2010; 104(2):114-121. http://dx.doi.org/10.1016/ S0022-3913(10)60103-5

14. Fischer J, Ebinger A, Hägi T, Stawarczyk B, Wenger A and Keller E. Mold filling and dimensional accuracy of titanium castings in a spinel-based investment. Dental Materials. 2009; 25(11):1376-1382. http://dx.doi.org/10.1016/j. dental.2009.06.012

15. Bezzon OL, Pedrazzi H, Zaniquelli O and Da Silva TB. Effect of casting technique on surface roughness and consequent mass loss after polishing of $\mathrm{NiCr}$ and $\mathrm{CoCr}$ base metal alloys: a comparative study with titanium. Journal of Prosthetic Dentistry. 2004; 92(3):274-277. http://dx.doi.org/10.1016/j. prosdent.2004.04.021

16. Eliopoulos D, Zinelis S and Papadopoulos T. The effect of investment material type on the contamination zone and mechanical properties of commercially pure titanium castings. Journal of Prosthetic Dentistry. 2005; 94(6):539-548. http:// dx.doi.org/10.1016/j.prosdent.2005.09.017

17. Guilin Y, Nan L, Yousheng L and Yining W. The effects of different types of investments on the alpha-case layer of titanium castings. Journal of Prosthetic Dentistry. 2007; 97(3):157-164. http://dx.doi.org/10.1016/j.prosdent.2007.01.005

18. Ida K, Togaya T, Tsutsumi S and Takeuchi M. Effect of Magnesia Investments in the Dental Casting of Pure Titanium or Titanium Alloys. Dental Materials Journal. 1982; 1(1):8-21. http://dx.doi.org/10.4012/dmj.1.8

19. Ban S, Watanabe T, Mizutani N, Fukui H, Hasegawa J and Nakamura H. Interfacial Oxidations of Pure Titanium and Titanium Alloys with Investments. Dental Materials Journal. 2000; 19(4):352-362. http://dx.doi.org/10.4012/ dmj.19.352

20. Miyakawa O, Watanabe K, Okawa S, Nakano S, Kobayashi M and Shiokawa N. Layered Structure of Cast Titanium Surface. Dental Materials Journal. 1989; 8(2):175-185. http://dx.doi. org/10.4012/dmj.8.175

21. Wakasa $\mathrm{K}$ and Yamaki M. Dental magnesia-based investment for casting titanium Journal of Materials Science Letters. 1994; 13(6):416-418. http://dx.doi.org/10.1007/ BF00278014

22. Nogueira F, Fais LMG, Fonseca RG and Adabo GL. The influence of short-heating-cycle investments on the quality of commercially pure titanium castings. Journal of Prosthetic Dentistry. 2010; 104(4):265-272. http://dx.doi.org/10.1016/ S0022-3913(10)60136-9

23. Cardoso FA, Innocentini MDM, Miranda MFS, Valenzuela FAO and Pandolfelli VC. Drying behavior of hydratable alumina-bonded refractory castables. European Ceramic Society. 2004; 24(5):797-802. http://dx.doi. org/10.1016/S0955-2219(03)00326-1

24. Innocentini MDM, Salomão R, Riberio C, Cardoso FA, Pandolfelli VC, Rettore RP et al. Permeability of fibercontaining refractory castables. Bulletin of the American Ceramic Society. 2002; 81(7):34-38.

25. Leal MB, Paulino SM, Pagnano VO and Bezzon OL. Influence of investment type and sprue number on the casting accuracy of titanium crown margins. Journal of Prosthetic Dentistry. 2006; 95(1):42-49. http://dx.doi.org/10.1016/j. prosdent.2005.11.004 